\title{
A Theoretical Method for Structural Design and Analysis of Crankshafts
}

\author{
Sergio Baragetti ${ }^{\text {a,b }}$ \\ ${ }^{a}$ Dept. of Management, Information and Production Engineering, University of Bergamo, Dalmine, Italy \\ ${ }^{b}$ GITT - Centre on Innovation Management and Technology Transfer, University of Bergamo, Bergamo, Italy \\ Email: sergio.baragetti@unibg.it
}

\begin{abstract}
:
The crankshaft is the crucial mechanical component in many machines and engines and its fatigue assessment is often very time consuming and expensive. The machine designer usually needs a simple theoretical model that would allow choosing the best material and the dimensions of the component in a quick and reliable way. The numerical finite element simulation of crankshafts should follow the first step of theoretical dimensioning with the aim of evaluating the stress-strain behaviour at the notched area to verify the component against fatigue failure. The development of an intermediate theoretical model would prove effective to reduce the time needed to reach a second approximation design of the crankshaft. The aim of this paper is to give the designer a theoretical procedure that allows determining the strain and stress state for verification of crankshafts. The model was developed in the case of crankshafts with two connecting rods and validated by means of numerical finite element modelling and analysis.
\end{abstract}

\section{KEYWORDS:}

Crankshaft; Theoretical model; Machine design; Reliability; Fatigue resistance.

\section{CITATION:}

S. Baragetti. 2015. A Theoretical Method for Structural Design and Analysis of Crankshafts, Int. J. Vehicle Structures \& Systems, 7(3), 92-99. doi:10.4273/ijvss.7.3.02

\section{NOMENCLATURE:}

a Axial reference coordinate of the crankshaft, in the plane of the structure

A Cross section area

$A_{\text {cheek }} \quad$ Cross section area of the cheek

$A_{\text {crankpin }}$ Cross section area of the crankpin

$A_{\text {crankshaft }}$ Cross section area of the crankshaft

$E \quad$ Longitudinal modulus of elasticity of the material

$G \quad$ Shear modulus of elasticity of the material

$I_{x}, I_{y}, I_{z} \quad$ Moment of inertia around the $x, y \& z$ direction respectively

$J_{\text {crankshaft }} \quad$ Moment of inertia of the crankshaft

$J_{\text {cheek }} \quad$ Moment of inertia of the cheek

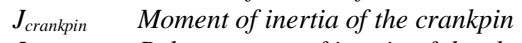

$J_{\text {tcheek }} \quad$ Polar moment of inertia of the cheek

$M_{a} \quad$ Moment around axis a

$M_{x} \quad$ Torque

$M_{y}, M_{z} \quad$ Moment around the $y \& z$ axis respectively

$M_{x}$, Torque for the fictitious structure in virtual work

$M_{y}{ }^{\prime}, M_{z}{ }^{\prime} \quad$ Moment around the $y \& z$ direction respectively for the fictitious structure in the principle of virtual work

$M f_{t}, M f_{n} \quad$ Bending along the $t$ and $n$ direction respectively

$M f_{x} \quad$ Bending along the $x$ direction

$M_{n}, M_{t} \quad$ Moment around axis $n$ and $t$ respectively

$M G_{n}, M G_{t}$ Weight along the $n$ and $t$ direction respectively

$n \quad$ Ref. coord. of the crankshaft, in the plane of the structure

$N \quad$ Axial force

$N^{\prime} \quad$ Axial force for the fictitious structure in the principle of virtual work

$N_{1}, N_{2} \quad$ External force acting on the crankshaft for the $1^{\text {st }}$ and $2^{\text {nd }}$ crank respectively, in the plane of the structure

$N_{A}, N_{B}, N_{C}$ Reaction force at support $A, B \& C$ respectively

$s \quad$ Local coordinate along the structure

$t \quad$ Reference coordinate of the crankshaft, perpendicular to the plane of the structure

$T_{1}, T_{2} \quad$ External force acting on the crankshaft for the $1^{\text {st }}$ and $2^{\text {nd }}$ crank respectively, in the plane perpendicular to one of the structure

$T_{A}, T_{B}, T_{C}$ Reaction force at support $A, B \& C$ respectively

$T_{n}, T_{t} \quad$ Shear force in the $n \& t$ direction respectively

$T_{y}, T_{z} \quad$ Shearforce in the $y$ and $z$ direction respectively

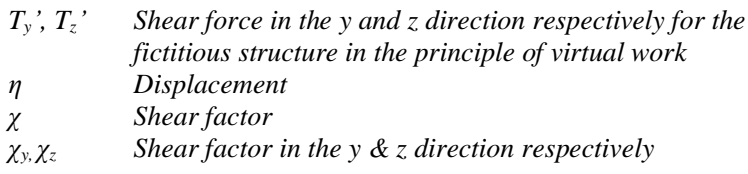

\section{Introduction}

The development of a new component first needs the assessment of the principal dimensions and then the optimization against fatigue, failure, wear and corrosion. The crankshaft is a historical component for the internal combustion engines and the literature gives a lot of design criteria and procedures for the development of new crankshafts or the optimization of existing ones [14]. Dynamic, vibration and fatigue failure analyses of this component can be found in many references such as $[5,6]$. References on surface mechanical or chemical treatments that could enhance the fatigue performances are also available [7-14]. Among such treatments surface rolling, nitriding and shot peening are the most used ones just because they induce a surface compression favourable stress state that inhibits nucleation and propagation of fatigue cracks. The aforementioned treatments have been used for many decades and still today they are commonly used to improve the reliability and fatigue resistance of many mechanical components. Mechanical treatments work harden the surface of the component, increasing its hardness and inducing compressive favourable residual stresses. A discrete enhancement in the fatigue resistance of the crankshaft can be achieved by rolling the rounded connections between the cheeks, the crankpins and the crankshaft journal areas. Better improvements might be achieved 
introducing new technologies such as the surface thin hard coatings that have been more and more used and introduced in many mechanical applications in the last few decades in order to improve wear and fatigue resistance of mechanical components [15-18].

PVD coatings in particular may represent a useful device to enhance the fatigue behaviour of crankshafts. The coating can be physically vapour deposited on the surface of the component at the areas where enhancement of wear, contact fatigue and fatigue resistance are needed. The coating deposition greatly improves the surface properties: hardness and residual stresses can reach quite high values and the residual stresses can approach surface compression values in the range of 1500-2500 $\mathrm{MPa}$, much higher than the compressive stresses induced by the mechanical or thermo-mechanical treatments. Bearing these last considerations in mind, the fatigue resistance of a crankshaft is not only dependent on the geometry and mechanical properties, but is surely strongly dependent on the load history, the induced stress state and residual stress state due to surface treatments or thin hard coatings, by the surface hardness and a lot of technological factors.

Theoretical and numerical methods allow the dimensioning and final design of the crankshaft and for a first evaluation of the principal dimensions of the component. The machine designer can reach a first approximation of the final shape of the crankshaft by implementing the procedures described in many useful and thoroughly adopted machine design books such as [19]. Such models allow dividing the hyperstatic component in many isostatic pieces and theoretically solving the problem of the stress evaluation in a very fast, even though quite approximate way. A better approximation can be achieved using higher order much more articulated procedures such as the one reported in [20]. Such procedures require the skills of an expert CAE machine design engineer: the model definition, analysis and results elaboration are usually time consuming and often need the validation through the development of experimental procedures (strain gages strain-stress measurement and displacements evaluation). Notwithstanding the model described in [20] requires the development of finite element procedures it is surely more reliable than the former. Moreover FEM modelling allows development of forecasting procedures able to take into consideration any combination of loads, boundary conditions, pre-stress, residual stresses and surface treatment [19-24].

In [20], authors developed experimental, numerical and theoretical procedures for the bending stress concentration evaluation of a marine diesel engine crankshaft and assessment of its fatigue resistance. Crack fillets stress concentrations were measured through the utilization of linear strain gauges on a full scale strain gauged crankshaft mounted, by means of appositely designed gripping devices, on a universal testing machine. 3D FEM models allowed the calculation of the bending and torsion stress concentration factors and proceed with the fatigue resistance analysis. In [21] a campaign of full scale experimental tests was carried out with the aim of validating numerical FEM models and to assess internal combustion engine crankshaft mechanical parameters. The residual stress field was mapped in the most stressed areas of the component. The step stress gradients at the fillets between the crankpin and the cheeks were investigated through the application of strain gages. The component was tested until complete rupture. The procedure proved to be useful to measure the surface residual stress filed induced by nitriding and might be applied in many other mechanical applications.

Bearing in mind these last considerations, the designer can choose between first approximations theoretical models or more advanced and sophisticated numerical procedures in order to reach a good level of knowledge of the stress and strain state of the crankshaft [27]. No "intermediate" model is available in the literature, between the very simple procedure and the advanced numerical time expensive one. A theoretical model that would prove to be much more effective than the simple approximate ones and at the same time would not be as time consuming and expensive as the numerical based ones, would allow to reach a good design level for the crankshaft. Such a design level may be enough in many engineering applications in which the need is to evaluate the strain-stress state and verify the fatigue resistance of the component. Aim of this paper is to give the machine designer a powerful theoretical tool to allow fast design of crankshafts. The model can be implemented in commercial mathematical codes such as MATLAB, MATHCAD or EXCEL.

\section{Crankshafts stress state evaluation}

In this paper the theoretical analysis of the stress-strain state of crankshafts with two connecting rods is reported. A crankshaft with multiple rods is shown in Fig. 1. The crankshaft moves two rods put in series one to the other in Fig. 2. The crankshaft can be restrained with a variable number of pin connections to the frame of the alternative pump: this means that the internal forces and bending actions of the structure might be more or less difficult to calculate according to the number of pin connections (isostatic or highly hyperstatic structure). The structure of Fig. 2 presents three supports: this crankshaft requires a quite high computational time and the evaluation of several hyperstatic forces. The two connecting rods crankshaft in Fig. 2 represents two cranks put on the same plane at $180^{\circ}$.

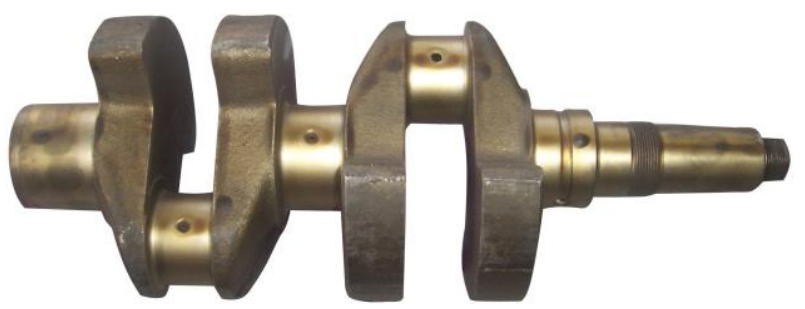

Fig. 1: Crankshaft example with 2 crankpins \& 2 connecting rods

The reduction in the fluctuation of the torque generated during the motion of the system in guaranteed by the presence of a fly wheel positioned at the right end of the component. The crankshaft is restrained in three sections by means of bearings that enable to simulate a simply supported connection in each of the supported 
sections of the crankshaft. The supports B and C are needed to sustain the crankshaft at the right side of the cranks because of the presence of the fly wheel. It was assumed that only the cheeks of the crankshaft have rectangular cross-sections while the other components of the crankshaft have circular cross-section, each with its appropriate diameter.

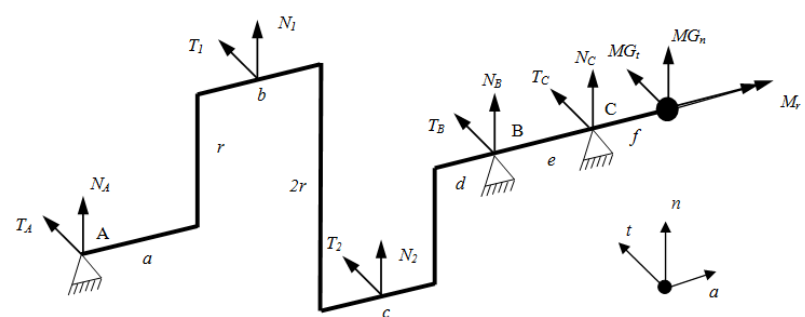

Fig. 2: Free body diagram for crankshaft with 2 connecting rods and 3 supports

\section{Evaluation of reactions}

The evaluation of the reaction forces at the supports of the crankshaft was developed for the structure with two connecting rods. The reaction forces at the constraints were calculated, as a function of the applied loads. The reaction forces were calculated according to the $n$ and $t$ directions (Fig. 2). The two connecting rods crankshaft presents three bearing supports with six reaction forces $N_{A}, T_{A}, N_{B}, T_{B}, N_{C}, T_{C}$ - and four acting forces - $N_{l}, T_{1}$, $N_{2}, T_{2}$ - as shown in Fig. 2. The unknown forces are then seven with the resistant torque $M_{r}$ (Fig. 2). The crankshaft has no axial load: no axial equilibrium equation along the $\mathrm{x}$ axis can be used to calculate the hyperstatic forces. This means that the unknown quantities are seven and only 5 equilibrium equations can be used. The principle of virtual work as below will be used to solve the problem and extract all the unknown reaction forces:

$$
\begin{aligned}
1 \eta_{a} & =\int_{l} \frac{N^{\prime} N}{E A} d s+\int_{l} \chi_{z} \frac{T_{z}^{\prime} T_{z}}{G A} d s+\int_{l} \chi_{y} \frac{T_{y}^{\prime} T_{y}}{G A} d s \\
& +\int_{l} \frac{M^{\prime}{ }_{z} M_{z}}{E I_{z}} d s+\int_{l} \frac{M^{\prime}{ }_{y} M_{y}}{E I_{y}} d s+\int_{l} \frac{M^{\prime}{ }_{x} M_{x}}{G J_{x}} d s
\end{aligned}
$$

Where $x, y$ and $z$ are respectively the three local coordinate axis for each component of the crankshaft; $x$ represents the local axial reference for the determination of the torque component. The reaction forces in A, B and $\mathrm{C}$ are the 6 unknown forces to be calculated through the principle of virtual work [25]. All the components of the crankshaft have been modelled in order to have a cylindrical cross section (crankshaft, crankpin) or a rectangular one (cheek). The hyperstatic reaction forces are the ones applied at point $\mathrm{A}$.

Two fictitious structures needed for the application of the principle of virtual work are shown in Fig. 3 where a unit force is applied at point $\mathrm{A}$ in the $n$ and $t$ directions respectively, the directions of each unknown hyperstatic reactions at $\mathrm{A}$. The procedure requires assigning an appropriate identification number to each component of the crankshaft, as shown in Fig. 4, in order to properly apply the integration required by the principle of virtual work for each component of the crankshaft.
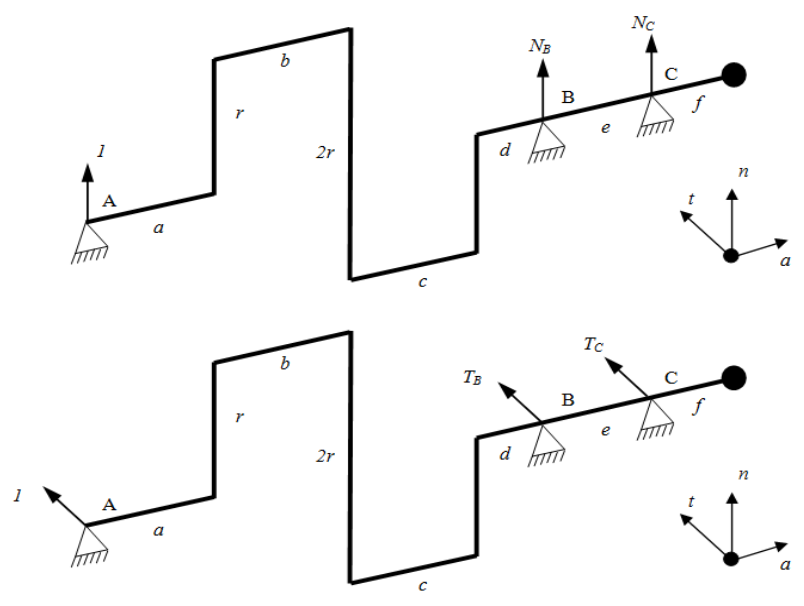

Fig. 3: Fictitious structures needed for the application of virtual work principle

The reaction forces in $\mathrm{B}$ and $\mathrm{C}$ will be calculated as a function of the hyper static actions in A, the unknown quantities of the problem (refer to Fig. 2 and Fig. 3 and Eqns. (2)-(11)).

$$
\begin{aligned}
& \Sigma M_{a}^{C}: 0=-T_{1} r+T_{2} r+M_{r} \\
& \begin{aligned}
\Sigma F_{n}: 0 & =N_{1}+N_{2}+M G_{n}+N_{A}+N_{B}+N_{C} \\
\Sigma M_{t}^{C}: 0 & =N_{1}\left(k_{8}+e\right)+N_{2}\left(k_{9}+e\right)-M G_{n} f \\
& +N_{A}\left(k_{5}+e\right)+N_{B} e
\end{aligned} \\
& \begin{aligned}
\Sigma F_{t}: 0 & =T_{1}+T_{2}+M G_{t}+T_{A}+T_{B}+T_{C} \\
\Sigma M_{n}^{C}: 0 & =T_{1}\left(k_{8}+e\right)+T_{2}\left(k_{9}+e\right)-M G_{t} f \\
& +T_{A}\left(k_{5}+e\right)+T_{B} e
\end{aligned}
\end{aligned}
$$

From Eqn. (2) we have:

$$
M_{r}=r\left(T_{1}-T_{2}\right)
$$

From Eqns. (3) and (4) we have:

$$
\begin{aligned}
& N_{B}=\frac{-1}{e}\left(\begin{array}{l}
\left.N_{A}\left(k_{5}+e\right)+N_{1}\left(k_{8}+e\right)+N_{2}\left(k_{9}+e\right)\right) \\
-M G_{n} f
\end{array}\right) \\
& N_{C}=\left(N_{A} k_{5}+N_{1} k_{8}+N_{2} k_{9}-M G_{n}(f+e)\right) / e
\end{aligned}
$$

From Eqns. (5) and (6) we have:

$$
\begin{aligned}
& T_{B}=\frac{-1}{e}\left(\begin{array}{l}
T_{A}\left(k_{5}+e\right)+T_{1}\left(k_{8}+e\right)+T_{2}\left(k_{9}+e\right) \\
-M G_{t} f
\end{array}\right) \\
& T_{C}=\left(T_{A} k_{5}+T_{1} k_{8}+T_{2} k_{9}-M G_{t}(f+e)\right) / e
\end{aligned}
$$

The constants $k_{1}$ to $k_{9}$ are defined as follows:

$$
\begin{aligned}
& k_{1}=a+0.5 b, \quad k_{2}=a+b, \quad k_{3}=a+b+0.5 c \\
& k_{4}=a+b+c, \quad k_{5}=a+b+c+d, \quad k_{6}=0.5 b+c \\
& k_{7}=b+c, \quad k_{8}=0.5 b+c+d, \quad k_{9}=0.5 c+d
\end{aligned}
$$

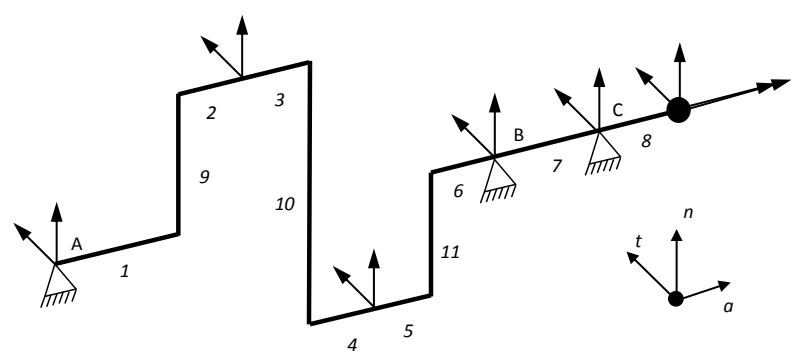

Fig. 4: Identification of the components of the crankshaft with two connecting rods 
With respect to Fig. 4, the internal actions for components 1 to 11 of the real structure are derived using in Eqns. (12) to (22) respectively.

$$
\begin{aligned}
& T_{n}=N_{A}, \quad T_{t}=T_{A}, \quad M_{x}=0, \\
& M f_{t}=N_{A} x, \quad M f_{n}=T_{A} x \\
& T_{n}=N_{A}, \quad T_{t}=T_{A}, \quad M_{x}=T_{A} r, \\
& M f_{n}=T_{A}(a+x), \quad M f_{t}=N_{A}(a+x) \\
& T_{n}=N_{A}+N_{1}, \quad T_{t}=T_{A}+T_{1}, \quad M_{x}=T_{A} r, \\
& M f_{t}=N_{A} k_{1}+\left(N_{A}+N_{1}\right) x \text {, } \\
& M f_{n}=T_{A} k_{1}+\left(T_{A}+T_{1}\right) x \\
& T_{n}=N_{A}+N_{1}, \quad T_{t}=T_{A}+T_{1}, \\
& M_{x}=\left(-T_{A}-2 T_{1}\right) r \text {, } \\
& M f_{t}=N_{A} k_{2}+0.5 N_{1} b+\left(N_{A}+N_{1}\right) x, \\
& M f_{n}=T_{A} k_{2}+0.5 T_{1} b+\left(T_{A}+T_{1}\right) x \\
& T_{n}=N_{A}+N_{1}+N_{2}, \quad T_{t}=T_{A}+T_{1}+T_{2}, \\
& M_{x}=\left(-T_{A}-2 T_{1}\right) r \text {, } \\
& M f_{t}=N_{A} k_{3}+0.5 N_{1} k_{7}+\left(N_{A}+N_{1}+N_{2}\right) x \text {, } \\
& M f_{n}=T_{A} k_{3}+0.5 T_{1} k_{7}+\left(T_{A}+T_{1}+T_{2}\right) x \\
& T_{n}=N_{A}+N_{1}+N_{2}, \quad T_{t}=T_{A}+T_{1}+T_{2}, \\
& M_{x}=\left(T_{2}-T_{1}\right) r \\
& M f_{t}=N_{A} k_{4}+N_{1} k_{6}+0.5 N_{2} c \\
& +\left(N_{A}+N_{1}+N_{2}\right) x \text {, } \\
& M f_{n}=T_{A} k_{4}+T_{1} k_{6}+0.5 T_{2} c \\
& +\left(T_{A}+T_{1}+T_{2}\right) x \\
& T_{n}=N_{A}+N_{1}+N_{2}+N_{B} \text {, } \\
& T_{t}=T_{A}+T_{1}+T_{2}+T_{B}, \quad M_{x}=\left(T_{2}-T_{1}\right) r, \\
& M f_{t}=N_{A} k_{5}+N_{1} k_{8}+N_{2} k_{9} \\
& +\left(N_{A}+N_{1}+N_{2}+N_{B}\right) x \text {, } \\
& M f_{n}=T_{A} k_{5}+T_{1} k_{8}+T_{2} k_{9} \\
& +\left(T_{A}+T_{1}+T_{2}+T_{B}\right) x \\
& T_{n}=N_{A}+N_{1}+N_{2}+N_{B}+N_{C}, \\
& T_{t}=T_{A}+T_{1}+T_{2}+T_{B}+T_{c}, \quad M_{x}=\left(T_{2}-T_{1}\right) r, \\
& M f_{t}=N_{A}\left(k_{5}+e\right)+N_{1}\left(k_{8}+e\right)+N_{2}\left(k_{9}+e\right) \\
& +N_{B} e+\left(N_{A}+N_{1}+N_{2}+N_{B}+N_{C}\right) x \\
& M f_{n}=T_{A}\left(k_{5}+e\right)+T_{1}\left(k_{8}+e\right)+T_{2}\left(k_{9}+e\right) \\
& +T_{B} e+\left(T_{A}+T_{1}+T_{2}+T_{B}+T_{C}\right) x \\
& N=-N_{A}, \quad T_{t}=T_{A}, \quad M_{x}=T_{A} a, \\
& M f_{t}=N_{A} a, \quad M f_{a}=T_{A} x \\
& N=N_{A}+N_{1}, \quad T_{t}=T_{A}+T_{1}, \\
& M_{x}=T_{A} k_{2}+0.5 T_{1} b \\
& M f_{t}=N_{A} k_{2}+0.5 N_{1} b \text {, } \\
& M f_{a}=T_{A} r-\left(T_{A}+T_{1}\right) x \\
& N=-N_{A}-N_{1}-N_{2}, \quad T_{t}=T_{A}+T_{1}+T_{2}, \\
& M_{x}=T_{A} k_{4}+T_{1} k_{6}+0.5 T_{2} c \text {, } \\
& M f_{t}=N_{A} k_{4}+N_{1} k_{6}+0.5 N_{2} c, \\
& M f_{a}=-T_{A} r-2 T_{1} r+\left(T_{A}+T_{1}+T_{2}\right) x
\end{aligned}
$$

By applying $N_{A}=1$ to the first fictitious structure, the internal forces for all the components of the crankshaft and reactions at supports $\mathrm{B}$ and $\mathrm{C}$ are calculated using Eqns. (23) to (25).

$$
\begin{aligned}
& \Sigma F_{n}: 0=1+N_{C}+N_{B} \\
& \Sigma M_{t}^{C}: 0=1 \cdot\left(k_{5}+e\right)+N_{B} e
\end{aligned}
$$

From Eqns. (23) and (24) we have:

$$
\begin{aligned}
& N_{B}=-\left(k_{5}+e\right) / e \\
& N_{C}=k_{5} / e
\end{aligned}
$$

The internal forces for components 1 to 11 of this first fictitious structure are reported in Eqns. (26) to (36) respectively.

$$
\begin{aligned}
& T_{n}=1, \quad M f_{t}=1 \cdot x, \quad M_{x}=0 \\
& T_{n}=1, \quad M f_{t}=1 \cdot(a+x), \quad M_{x}=0 \\
& T_{n}=1, \quad M f_{t}=1 \cdot\left(k_{1}+x\right), \quad M_{x}=0 \\
& T_{n}=1, \quad M f_{t}=1 \cdot\left(k_{2}+x\right), \quad M_{x}=0 \\
& T_{n}=1, \quad M f_{t}=1 \cdot\left(k_{3}+x\right), \quad M_{x}=0 \\
& T_{n}=1, \quad M f_{t}=1 \cdot\left(k_{4}+x\right), \quad M_{x}=0 \\
& T_{n}=-k_{5} / e, \\
& M f_{t}=1 \cdot k_{5}(1-x / e), \quad M_{x}=0 \\
& T_{n}=0, \quad M f_{t}=0, \quad M_{x}=0 \\
& N=1, \quad M f_{t}=a, \quad M_{x}=0 \\
& N=1, \quad M f_{t}=k_{2}, \quad M_{x}=0 \\
& N=1, \quad M f_{t}=k_{4}, \quad M_{x}=0
\end{aligned}
$$

By applying $T_{A}=1$ to the second fictitious structure, the internal forces for all the component of the crankshaft will be calculated with a unit force along the $t$ direction at restraint $\mathrm{A}$. The reaction forces at restraints $\mathrm{B}$ and $\mathrm{C}$ are calculated as:

$$
\begin{aligned}
& \Sigma F_{t}: 0=1+T_{C}+T_{B} \\
& \Sigma M_{n}^{C}: 0=1 \cdot\left(k_{5}+e\right)+T_{B} e
\end{aligned}
$$

From Eqns. (37) and (38) we have:

$$
\begin{aligned}
& T_{B}=-\left(k_{5}+e\right) / e \\
& T_{C}=k_{5} / e
\end{aligned}
$$

The internal forces for components 1 to 11 of this second fictitious structure are reported in Eqns. (40)-(50) respectively.

$$
\begin{aligned}
& T_{t}=1, \quad M f_{n}=1 \cdot x, \quad M_{x}=0 \\
& T_{t}=1, \quad M f_{n}=1 \cdot(a+x), \quad M_{x}=r \\
& T_{t}=1, \quad M f_{n}=1 \cdot\left(k_{1}+x\right), \quad M_{x}=r \\
& T_{t}=1, \quad M f_{n}=1 \cdot\left(k_{2}+x\right), \quad M_{x}=-r \\
& T_{t}=1, \quad M f_{n}=1 \cdot\left(k_{3}+x\right), \quad M_{x}=-r \\
& T_{t}=1, \quad M f_{n}=1 \cdot\left(k_{4}+x\right), \quad M_{x}=0 \\
& T_{t}=-k_{5} / e, \\
& M f_{n}=1 \cdot k_{5}(1-x / e), \quad M_{x}=0 \\
& T_{t}=0, \quad M f_{n}=0, \quad M_{x}=0 \\
& T_{t}=1, \quad M f_{a}=x, \quad M_{x}=a \\
& T_{t}=1, \quad M f_{a}=r-x, \quad M_{x}=a \\
& T_{t}=1, \quad M f_{a}=x-r, \quad M x=k_{4}
\end{aligned}
$$

The equation of the principle of virtual work can be written for the first fictitious structure considering that the displacement in the $n$ direction at the restrained end $\mathrm{A}$ is equal to zero as derived in Eqn. (51). 


$$
\begin{aligned}
& 1 \cdot \delta A=0=\int_{0}^{a} \frac{N_{A} x^{2}}{E J} d x+\int_{0}^{a} \chi \frac{N_{A}}{G A} d x \\
& +\int_{0}^{0.5 b} \frac{N_{A}(a+x)^{2}}{E J} d x+\int_{0}^{0.5 b} \chi \frac{N_{A}}{G A} d x \\
& +\int_{0}^{0.5 b} \frac{1}{E J}\left(N_{A} k_{1}+\left(N_{A}+N_{1}\right) x\left(k_{1}+x\right)\right) d x \\
& +\int_{0}^{0.5 b} \frac{\chi}{G A}\left(N_{A}+N_{1}\right) d x+\int_{0}^{0.5 c} \chi \frac{N_{A}+N_{1}}{G A} d x \\
& +\int_{0}^{0.5 c} \frac{1}{E J}\left(\begin{array}{l}
N_{A} k_{2}+0.5 N_{1} b \\
+\left(N_{A}+N_{1}\right) x\left(k_{2}+x\right)
\end{array}\right) d x \\
& +\int_{0}^{0.5 c} \frac{1}{E J}\left(\begin{array}{l}
N_{A} k_{2}+0.5 N_{1} b+\left(N_{A}+N_{1}\right) \\
x\left(k_{3}+x\right)
\end{array}\right) d x \\
& +\int_{0}^{0.5 c} \frac{\chi}{G A}\left(N_{A}+N_{1}+N_{2}\right) d x \\
& +\int_{0}^{d} \frac{1}{E J}\left(\begin{array}{l}
N_{A} k_{4}+N_{1} k_{6}+0.5 N_{2} c+\left(N_{A}\right. \\
\left.+N_{1}+N_{2}\right) x\left(k_{4}+x\right)
\end{array}\right) d x \\
& +\int_{0}^{d} \chi \frac{N_{A}+N_{1}+N_{2}}{G A} d x+\int_{0}^{r} \frac{N_{A} a^{2}}{E J} d x \\
& +\int_{0}^{e} \frac{1}{E J}\left(\begin{array}{l}
N_{A} k_{5}+N_{1} k_{8}+N_{2} k_{9}+\left(N_{A}+\right. \\
\left.N_{1}+N_{2}+N_{B}\right) x k_{5}(1-x / e)
\end{array}\right) d x \\
& +\int_{0}^{e} \frac{\chi}{e^{2} G A}\left(\begin{array}{l}
N_{A} k_{5}+N_{1} k_{8}+N_{2} k_{9} \\
\left.-M G_{n} f\right) k_{5}
\end{array}\right) d x \\
& +\int_{0}^{r} \frac{N_{A}}{E A} d x+\int_{0}^{2 r} \frac{N_{A} k_{2}+0.5 N_{1} b}{E J} k_{2} d x \\
& +\int_{0}^{2 r} \frac{N_{A}+N_{1}}{E A} d x+\int_{0}^{r} \frac{1}{E J}\left(\begin{array}{l}
N_{A} k_{4}+N_{1} k_{6} \\
+0.5 N_{2} c
\end{array}\right) k_{4} d x \\
& +\int_{0}^{r} \frac{N_{A}+N_{1}+N_{2}}{E A} d x
\end{aligned}
$$

Where $A, J$ and $J_{t}$ and, respectively the area, the inertia moment, the torsion inertia moment and the shear factor, are different for each of the components of the crankshaft. The value of $N_{B}$ from Eqn. (25) in now put into Eqn. (51), and an equation with one unknown quantity is obtained. Afterwards we integrate Eqn. (51) to obtain Eqn. (52). It should be noted that each of the component of the crankshaft has its own inertia properties.

$$
\begin{aligned}
& 0=\frac{1}{E J}\left(\begin{array}{l}
N_{A}\left(a^{2} b / 2+b^{3} / 24+a b^{2} / 4\right)+0.5 N_{A} \\
k_{1} b(a+0.75 b)+\left(N_{1}+N_{A}\right)\left[b^{2}(a+\right. \\
5 b / 6) / 8]+\left(N_{A}+N_{1}\right) c^{2}\left(k_{2}+c / 3\right) / 8 \\
+\left[N_{A} k_{2}+0.5 N_{1} b\right]\left(k_{2}+0.25 c\right) c / 2 \\
+\left[N_{A} k_{3}+N_{1} k_{7} / 2\right]\left(k_{2}+0.75 c\right) \\
+\left(N_{A}+N_{1}+N_{2}\right) c^{2}\left(k_{2}+5 c / 6\right) / 8 \\
+\left[N_{A} k_{4}+N_{1} k_{6}+N_{2} c / 2\right] d\left(k_{4}+d / 2\right) \\
+\left(N_{A}+N_{1}+N_{2}\right) d^{2}\left(k_{4}+2 d / 3\right) / 2 \\
+N_{A} a^{2} r+N_{A} a^{3}+\left[N_{A} k_{4}+N_{1} k_{4}\right. \\
\left.+N_{2} c / 2\right] k_{4} r+\left[N_{A} k_{5}+N_{1} k_{8}+N_{2} k_{9}\right] \\
k_{5} e / 3+2 N_{A} k_{2}{ }^{2} r+M G_{n} k_{5} e f / 6
\end{array}\right) \\
& +\frac{\chi}{G J}\left(\begin{array}{l}
N_{A}\left(k_{5}+k_{5}{ }^{2} / e\right)+N_{1}\left(k_{8}+k_{5} k_{8} / e\right)+ \\
N_{2}\left(k_{9}+k_{5} k_{9} / e\right)-M_{n} k_{5} f / e
\end{array}\right) \\
& +\frac{1}{E J} N_{1} k_{2} b r+\frac{1}{E A}\left(4 N_{A}+3 N_{1}+N_{2}\right) r
\end{aligned}
$$

It is possible to summarize Eqn. (52) into Eqn. (53):

$$
P N_{A}+Q N_{1}+R N_{2}+S M G_{n}=0
$$

$P, Q, R$ and $S$ in (53) can be obtained by putting together all the terms that respectively multiply $N_{A}, N_{1}, N_{2}$ and $M G_{n}$ in Eqn. (52). The values of $P, Q, R$ and $S$ in Eqn. (53) are reported in Eqns. (54)-(57).

$$
\begin{aligned}
& P=\frac{1}{E J_{\text {crankshaft }}}\left(\begin{array}{l}
a^{3} / 3+k_{4} d\left(k_{4}+0.5 d\right)+d^{2} \\
\left(0.5 k_{4}+d / 3\right)+k_{5}{ }^{2} e / 3
\end{array}\right) \\
& +\frac{r}{E J_{\text {cheek }}}\left(a^{2}+k_{2}{ }^{2}+k_{4}{ }^{2}\right) \\
& +\frac{1}{E_{\text {crankpin }}}\left(\begin{array}{l}
0.5 b\left(a^{2}+b^{2} / 12+0.5 a b\right) \\
+0.5 b k_{1}(a+0.75 b)+b^{2}(a \\
+5 b / 6) / 8+0.5 k_{2} c\left(k_{2}\right. \\
+0.25 c)+c^{2}\left(k_{2}+c / 3\right) / 8 \\
+0.5 k_{3} c\left(k_{2}+0.75 c\right)+c^{2}\left(k_{2}\right. \\
+5 c / 6) / 8
\end{array}\right) \\
& +\frac{4 r}{E A_{\text {cheek }}}+\frac{\chi k_{7}}{G A_{\text {crankpin }}}+\frac{\chi\left(a+d+k_{5}^{2} / e\right)}{G A_{\text {crankshaft }}} \\
& Q=\frac{1}{E J_{\text {crankshaft }}}\left(\begin{array}{l}
k_{6} d\left(k_{4}+0.5 d\right)+d^{2}\left(0.5 k_{4}\right. \\
+d / 3)+k_{8} k_{5} e / 3
\end{array}\right) \\
& +\frac{r}{E J_{\text {cheek }}}\left(b k_{2}+k_{4} k_{6}\right) \\
& +\frac{1}{E J_{\text {crankpin }}}\left(\begin{array}{l}
b^{2}(a+5 b / 6) / 8+0.25 b c\left(k_{2}\right. \\
+0.25 c)+c^{2}\left(k_{2}+c / 3\right) / 8 \\
+0.25 k_{7} c\left(k_{2}+0.25 c\right)+c^{2} \\
\left(k_{2}+5 c / 6\right) / 8
\end{array}\right) \\
& +\frac{3 r}{E A_{\text {cheek }}}+\frac{\chi k_{6}}{G A_{\text {crankpin }}}+\frac{\chi\left(d+k_{5} k_{8} / e\right)}{G A_{\text {crankshaft }}} \\
& R=\frac{1}{E J_{\text {crankshaft }}}\left(\begin{array}{l}
0.5 c d\left(k_{4}+0.5 d\right)++d^{2}\left(0.5 k_{4}\right. \\
+d / 3)+k_{9} k_{5} e / 3
\end{array}\right) \\
& +\frac{0.5 r k_{4} c}{E J_{\text {cheek }}}+\frac{1}{E J_{\text {crankpin }}}\left(c^{2}\left(k_{2}+5 c / 6\right) / 8\right) \\
& +\frac{r}{E A_{\text {cheek }}}+\frac{0.5 \chi c}{G A_{\text {crankpin }}}+\frac{\chi\left(d+k_{5} k_{9} / e\right)}{G A_{\text {crankshaft }}} \\
& S=\frac{k_{5} e f / 6}{E J_{\text {crankshaft }}}-\frac{\chi k_{5} f / e}{G A_{\text {crankshaft }}}
\end{aligned}
$$

Now $N_{A}$ can be calculated:

$$
N_{A}=-\left(B N_{1}+C N_{2}+D M G_{n}\right) / A
$$

The equation of the principle of virtual work can be written for the second fictitious structure considering that the displacement in the $t$ direction at the restrained end $\mathrm{A}$ is equal to zero as derived in Eqn. (59).

$$
\begin{aligned}
& \text { 1. } \delta A=0=\int_{0}^{a} \frac{T_{A} x^{2}}{E J} d x+\int_{0}^{a} \frac{\chi T_{A}}{G A} d x \\
& +\int_{0}^{0.5 b} \frac{T_{A}(a+x)^{2}}{E J} d x+\int_{0}^{0.5 b} \frac{\chi T_{A}}{G A} d x \\
& +\int_{0}^{0.5 b} \frac{1}{E J}\left(T_{A} k_{1}+\left(T_{A}+T_{1}\right) x\right)\left(k_{1}+x\right) d x \\
& +\int_{0}^{0.5 c} \frac{1}{E J}\left(\begin{array}{l}
T_{A} k_{2}+0.5 T_{1} b \\
+\left(T_{A}+T_{1}\right) x
\end{array}\right)\left(k_{2}+x\right) d x
\end{aligned}
$$




$$
\begin{aligned}
& +\int_{0}^{0.5 c} \frac{1}{E J}\left(\begin{array}{l}
T_{A} k_{3}+0.5 T_{1} k_{7} \\
+\left(T_{A}+T_{1}+T_{2}\right) x
\end{array}\right)\left(k_{3}+x\right) d x \\
& +\int_{0}^{d} \frac{1}{E J}\left(\begin{array}{l}
T_{A} k_{4}+T_{1} k_{6}+0.5 T_{2} c \\
+\left(T_{A}+T_{1}+T_{2}\right) x
\end{array}\right)\left(k_{4}+x\right) d x \\
& +\int_{0}^{0.5 b} \frac{\chi}{G A}\left(T_{A}+T\right) d x+\int_{0}^{0.5 c} \frac{\chi}{G A}\left(T_{A}+T_{1}\right) d x \\
& +\int_{0}^{e} \frac{1}{E J}\left(\begin{array}{l}
T k_{5}+T_{1} k_{8}+T_{2} k_{9} \\
+\left(T_{A}+T_{1}+T_{2}\right. \\
\left.+T_{B}\right) x
\end{array}\right) k_{5}(1-x / e) d x \\
& +\int_{0}^{r} \frac{T_{A} x^{2}}{E J} d x+\int_{0}^{2 r} \frac{T_{A} r-\left(T_{A}+T_{1}\right) x}{E J}(r-x) d x \\
& +\int_{0}^{r} \frac{\left(T_{A}+T_{1}+T_{2}\right) x-r\left(2 T_{1}+T_{A}\right)}{E J}(x-r) d x \\
& +\int_{0}^{r} \frac{T_{A} a^{2}}{G J_{t}} d x+\int_{0}^{0.5 c} \frac{\chi}{G A}\left(T_{A}+T_{1}+T\right) d x \\
& +\int_{0}^{2 r} \frac{T_{A} k_{2}+0.5 T_{1} b}{G J_{t}} k_{2} d x \\
& +\int_{0}^{r} \frac{1}{G J_{t}}\left(T_{A} k_{4}+T_{1} k_{6}+0.5 T_{2} c\right) k_{4} d x \\
& +\int_{0}^{c} \frac{2 T_{1}+T_{A}}{G J_{t}} r^{2} d x+\int_{0}^{b} \frac{T_{A}}{G J_{t}} r^{2} d x \\
& +\int_{0}^{d} \frac{\chi\left(T_{A}+T_{1}+T_{2}\right)}{G A} d x+\int_{0}^{e} \frac{\chi k_{5}}{G A e}\left(\begin{array}{l}
T_{A}+T_{1} \\
+T_{2}+T_{B}
\end{array}\right) d x \\
& +\int_{0}^{r} \frac{\chi T_{A}}{G A} d x+\int_{0}^{2 r} \frac{\chi\left(T_{A}+T_{1}\right)}{G A} d x \\
& +\int_{0}^{r} \frac{\chi\left(T_{A}+T_{1}+T_{2}\right)}{G A} d x
\end{aligned}
$$

Where $A, J, J_{t}$ and $\chi$, are the area, inertia moment, torsion inertia moment and shear factor respectively for each of the components of the crankshaft. The value of $T_{B}$ from Eqn. (10) is now put into Eqn. (59), and an equation with only one unknown quantity is obtained. Afterwards we integrate Eqn. (59); bearing in mind that each of the component of the crankshaft has its own inertia properties as noted in Eqn. (60).

$$
\begin{aligned}
0=\frac{1}{E J}\left(\begin{array}{l}
T_{A} a^{3} / 3+T_{A}\left(0.5 a^{2} b+b^{3} / 24\right. \\
\left.+0.25 a b^{2}\right)+0.5 T_{A} k_{1} b(a \\
+0.75 b)+\left(T_{1}+T_{A}\right) \\
\left(b^{2}(a+5 b / 6) / 8\right)+\left(T_{A}+T_{1}\right) c^{2} \\
\left(k_{2}+c / 3\right) / 8
\end{array}\right) \\
+\frac{1}{E J}\left(\begin{array}{l}
\left(T_{A} k_{2}+0.5 T_{1} b\right)\left(k_{2}+0.25 c\right) \frac{c}{2}+ \\
0.5\left(T_{A} k_{3}+0.5 T_{1} k_{7}\right) c\left(k_{2}+0.75 c\right) \\
+\left(T_{A}+T_{1}+T_{2}\right) c^{2}\left(k_{2}+5 c / 6\right) / 8
\end{array}\right) \\
+\frac{1}{E J}\left(\begin{array}{l}
\left(T_{A} k_{4}+T_{1} k_{6}+0.5 T_{2} c\right) d\left(k_{4}+0.5 d\right) \\
+0.5\left(T_{A}+T_{1}+T_{2}\right) d^{2}\left(k_{4}+2 d / 3\right) \\
+T_{A} r^{3} / 3+2\left(T_{A}+T_{1}\right) r^{3} / 3
\end{array}\right) \\
+\frac{1}{E J}\left(\begin{array}{l}
\left(2 T_{1}+T_{A}\right) r^{3} / 2-\left(T_{1}+T_{2}+T_{A}\right) \\
r^{3} / 6+\left[T_{A} k_{5}+T_{1} k_{8}+T_{2} k_{9}\right] k_{5} e / 3
\end{array}\right) \\
+\frac{M G_{t} k_{5} e f / 6}{E J}+\frac{\chi}{G A} T_{A}\left(k_{5}+k_{5}^{2} / e\right)
\end{aligned}
$$

$$
\begin{aligned}
& +\frac{\chi}{G A}\left(4 T_{A}+3 T_{1}+T_{2}\right) r \\
& +\frac{\chi}{G A}\left(\begin{array}{l}
T_{1}\left(k_{8}+k_{5} k_{8} / e\right)+T_{2} \\
\left(k_{9}+k_{5} k_{9} / e\right)-M G_{t} k_{5} f / e
\end{array}\right) \\
& +\frac{1}{G J t}\left(\begin{array}{l}
T_{A} a^{2} r+T_{A} r^{2} b+2 T_{A} k_{2}^{2} r \\
+T_{1} k_{2} b r+\left(2 T_{1}+T_{A}\right) r^{2} c \\
+\left(T_{A} k_{4}+T_{1} k_{6}+0.5 T_{2} c\right) k_{4} r
\end{array}\right)
\end{aligned}
$$

It is possible to summarize Eqn. (60) into Eqn. (61):

$$
E T_{A}+F T_{1}+G T_{2}+H M G_{t}=0
$$

The terms $E, F, G$ and $H$ in Eqn. (61), can be obtained by putting together all the terms that respectively multiply $T_{A}, T_{1}, T_{2}$, and $M G_{t}$ in Eqn. (60) and are reported in Eqns. (62) to (65) respectively.

$$
\begin{aligned}
& E=\frac{1}{E J_{\text {crankshaft }}}\left(\begin{array}{l}
a^{3} / 3+k_{4} d\left(k_{4}+0.5 d\right)+d^{2} \\
\left(0.5 k_{4}+d / 3\right)+k_{5}{ }^{2} e / 3
\end{array}\right) \\
& +\frac{4 r / 3}{E J_{\text {cheek }}}+\frac{1}{E J_{\text {crankpin }}}\left(\begin{array}{l}
0.5 b\left(a^{2}+b^{2} / 12\right. \\
+0.5 a b)+0.5 b k_{1} \\
(a+0.75 b)+b^{2}(a \\
+5 b / 6) / 8+0.5 k_{2} c \\
\left(k_{2}+0.25 c\right)+c^{2}(a \\
+b+c / 3) / 8+0.5 k_{3} \\
c\left(k_{2}+0.75 c\right)+c^{2}\left(k_{2}\right. \\
+5 c / 6) / 8
\end{array}\right) \\
& +\frac{r^{2} k_{7}}{G J_{\text {tcheek }}}+\frac{r}{G J_{\text {tcheek }}}\left(a^{2}+k_{2}^{2}+k_{4}^{2}\right)+\frac{4 r \chi_{\text {cheek }}}{G A_{\text {cheek }}} \\
& +\frac{\chi k_{7}}{G A_{\text {crankpin }}}+\frac{\chi}{G A_{\text {crankshaft }}}\left(a+d+k_{5}^{2} / e\right) \\
& F=\frac{1}{E J_{\text {crankshaft }}}\left(\begin{array}{l}
k_{6} d\left(k_{4}+0.5 d\right)+d^{2}\left(0.5 k_{4}\right. \\
+d / 3)+k_{8} k_{5} e / 3
\end{array}\right) \\
& +\frac{3 r^{3} / 2}{E J_{\text {cheek }}}+\frac{2 r^{2} c}{G J t_{\text {crankpin }}}+\frac{\chi k_{6}}{G A_{\text {crankpin }}} \\
& +\frac{1}{E J_{\text {crankpin }}}\left(\begin{array}{l}
b^{2}(a+5 b / 6) / 8+0.25 b c\left(k_{2}\right. \\
+0.25 c)+c^{2}(a+b+c / 3) / 8 \\
+0.25 k_{7} c\left(k_{2}+0.75 c\right)+c^{2}(a \\
+b+5 c / 6) / 8
\end{array}\right) \\
& +\frac{b r k_{2}+k_{4} k_{6} r}{G J_{\text {tcheek }}}+\frac{\chi_{\text {cheek }} 3 r}{G A_{\text {cheek }}}+\frac{\chi\left(d+k_{5} k_{8} / e\right)}{G A_{\text {crankshaft }}} \\
& G=\frac{1}{E J_{\text {crankshaft }}}\left(\begin{array}{l}
0.5 c d\left(k_{4}+0.5 d\right)+d^{2}\left(0.5 k_{4}\right. \\
+d / 3)+k_{9} k_{5} e / 3
\end{array}\right) \\
& -\frac{r^{3} / 6}{E J_{\text {cheek }}}+\frac{1}{E J_{\text {crankpin }}}\left(c^{2}\left(k_{2}+5 c / 6\right) / 8\right) \\
& +\frac{0.5 c r k_{4}}{G J_{\text {tcheek }}}+\frac{r \chi_{\text {cheek }}}{G A_{\text {cheek }}}+\frac{0.5 \chi c}{G A_{\text {crankpin }}} \\
& +\chi \frac{\left(d+k_{5} k_{9} / e\right)}{G A_{\text {crankshaft }}} \\
& H=\frac{k_{5} e f / 6}{E J_{\text {crankshaft }}}-\frac{\chi k_{5} f / e}{G A_{\text {crankshaft }}}
\end{aligned}
$$

Now $T_{A}$ can be calculated:

$$
T_{A}=-\left(B T_{1}+C T_{2}+D M G_{t}\right) / A
$$


Once the hyperstatic force $T_{A}$ is known, the reaction components in the $n$ direction for the supports $\mathrm{B}$ and $\mathrm{C}$ can be calculated by using Eqns. (10) and (11). The architecture of implemented theoretical model in MATLAB is shown in Fig. 5.

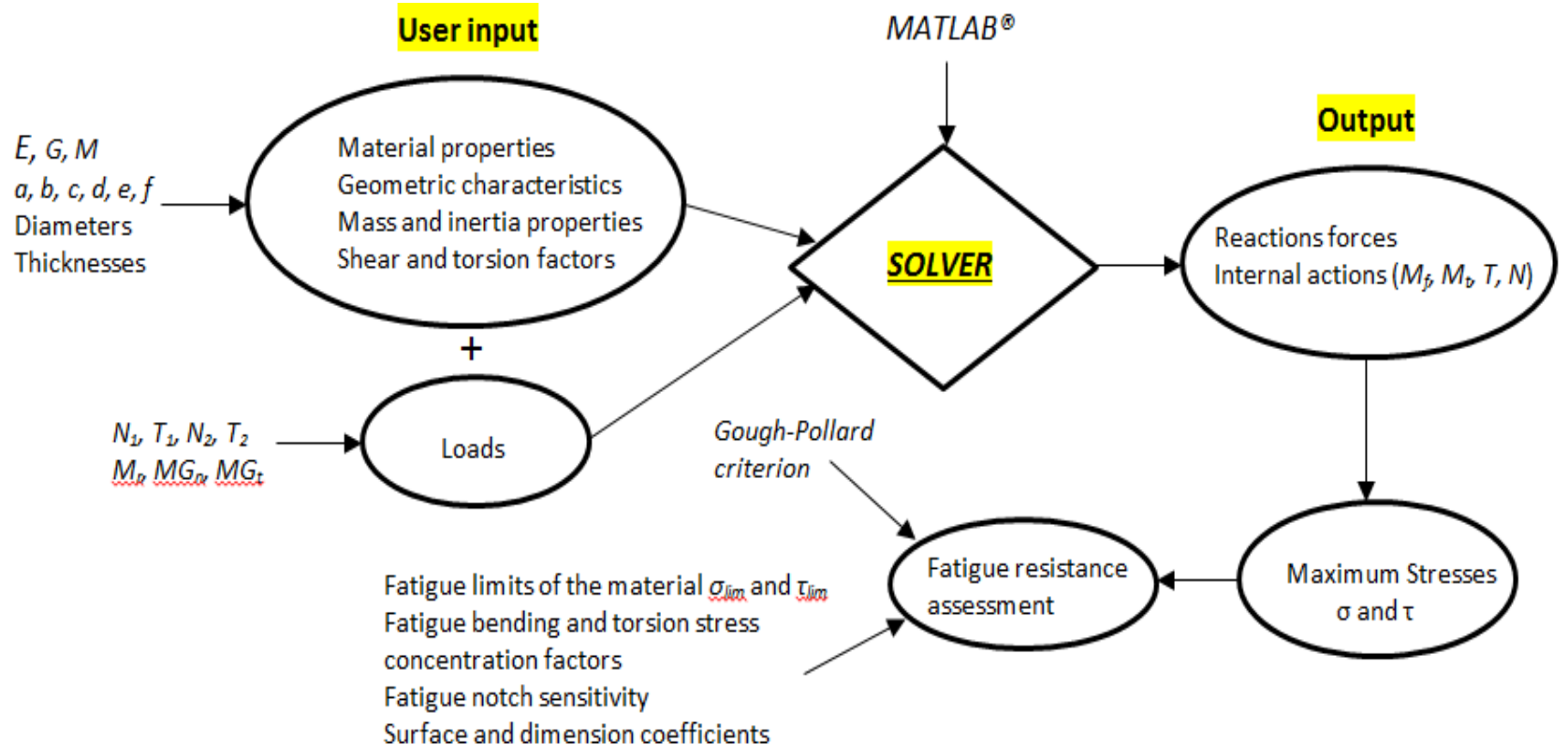

Fig. 5: Architecture of the theoretical model implemented in MATLAB

\section{Validation of theoretical method}

The results of theoretical model were verified through the development of a numerical FEM commercial code ABAQUS [26]. A sample crankshaft was considered for the verification and validation. A 3-D beam model of the crankshaft was developed. Each of the components of the crankshaft $a, b, c, d, e, f$ and $r$ was divided into ten beam elements having linear shape functions. A comparison was made between the values of the reaction forces and of the internal forces resulting bending, axial, shear and torsion actions. These were useful latter for the fatigue resistance evaluation of the component. The sectional properties assigned. Table 1 lists the geometry and principal elastic material properties of the crankshaft. Linear elastic analyses were preformed. Tables 2 and 3 give the comparison between the numerical results and the theoretical ones. All the values in Table 3 were obtained by dividing each quantity by $T_{A}$, obtained for the applied load $M G_{t}$. Negligible differences in results were observed between the theoretical method and the numerical model.

Table 1: Geometry and material characteristics

\begin{tabular}{cc}
\hline Characteristics & Value \\
\hline$E$ & $206 \mathrm{GPa}$ \\
$G$ & $80 \mathrm{GPa}$ \\
$b / a$ & 1.8 \\
$c / a$ & 1.8 \\
$d / a$ & 1.0 \\
$e / a$ & 1.5 \\
$f / a$ & 4.0 \\
Diameter of the crankshaft & 1.5 \\
Diameter of each crankpin & 1.4 \\
Thickness of each cheek & 1.9 \\
Height of each cheek & 0.8 \\
Torsion factor (for $J_{t}$ ) & 0.25 \\
\hline
\end{tabular}

Table 2: First fictitious structure results summary

\begin{tabular}{ccccc}
\hline Reactions & Applied load & Numeric. & Theor. & $\Delta \%$ \\
\hline \multirow{3}{*}{$N_{A}$} & $N_{l}=10 \mathrm{kN}$ & -20.98 & -20.98 & 0.03 \\
& $N_{2}=10 \mathrm{kN}$ & -6.12 & -6.11 & 0.13 \\
& $M G_{n}=10 \mathrm{kN}$ & 1.07 & 1.05 & 1.42 \\
\multirow{2}{*}{$N_{B}$} & $N_{l}=10 \mathrm{kN}$ & -56.72 & -56.76 & -0.07 \\
& $N_{2}=10 \mathrm{kN}$ & 77.60 & 77.65 & -0.06 \\
& $M G_{n}=10 \mathrm{kN}$ & 159.36 & 159.44 & -0.05 \\
\multirow{2}{*}{$N_{C}$} & $N_{l}=10 \mathrm{kN}$ & 34.49 & 34.52 & -0.07 \\
& $N_{2}=10 \mathrm{kN}$ & 40.51 & 40.54 & 0.93 \\
& $M G_{n}=10 \mathrm{kN}$ & -203.64 & -203.71 & 1.93 \\
\hline
\end{tabular}

Table 3: Second fictitious structure results summary

\begin{tabular}{ccccc}
\hline Reactions & Applied load & Numeric. & Theor. & $\Delta \%$ \\
\hline \multirow{3}{*}{$T_{A}$} & $T_{1}=10 \mathrm{kN}$ & -21.95 & -21.96 & -0.06 \\
& $T_{2}=10 \mathrm{kN}$ & -6.06 & -6.06 & -0.13 \\
& $M G_{t}=10 \mathrm{kN}$ & 1.03 & 1.00 & 2.47 \\
\multirow{3}{*}{$T_{B}$} & $T_{1}=10 \mathrm{kN}$ & -51.26 & -51.17 & 0.17 \\
& $T_{2}=10 \mathrm{kN}$ & -77.96 & -77.90 & 0.07 \\
& $M G_{t}=10 \mathrm{kN}$ & 159.59 & 159.73 & -0.09 \\
\multirow{2}{*}{$T_{C}$} & $T_{l}=10 \mathrm{kN}$ & 30.04 & 29.97 & 0.24 \\
& $T_{2}=10 \mathrm{kN}$ & 40.87 & 40.82 & 0.11 \\
& $M G_{t}=10 \mathrm{kN}$ & -204.18 & -204.29 & -0.06 \\
\hline
\end{tabular}

\section{Conclusions}

A theoretical method that allows the designer to determine the strain and stressing state for verifying the crankshafts in different applications was presented. A crankshaft with two connecting rods was considered. The virtual work principle was used to assess the theoretical formulae useful to extract all the reaction forces and the internal actions. A numerical linear beam finite element model of the two connecting rod crankshaft was developed in order to check the correctness of the theoretical model. Theoretical results are in good agreement with those from the numerical 
model. The presented theoretical procedure can be implemented in commercial mathematical software such as MATLAB. The procedure developed for crankshafts with 2 rods and 3 supports can be extended to as many rods and supports as required. After the first step dimensioning of the crankshaft, an accurate 3-D finite element model of the component can be developed to quantify the stress concentration factors and verify the fatigue resistance with a better accuracy.

\section{REFERENCES:}

[1] A. Garro and V. Vullo. 1978. Some consideration on the evaluation of thermal stresses in combustion engine, SAE Technical Paper 780664, 2563-2592.

[2] E. Bargis, A. Garro and V. Vullo. 1980. Crankshaft design and evaluation - Parts 1-3, Proc. Int. Conf. Reliability, Stress Analysis and Failure Prevention, San Francisco, California.

[3] C. Delprete, R. Molisano, D. Micelli and E. Pisanò. 2001. Analisi vibrazionale e strutturale degli alberi a gomiti. Proc. Convegno AIAS 2001, Alghero, Italy, 1427-1435.

[4] A. Garro. 1992. Progettazione Strutturale del Motore, Levrotto \& Bella, Torino, Italy.

[5] W.Y. Chien, J. Pan, D. Close and S. Ho. 2005. Fatigue analysis of crankshaft sections under bending with consideration of residual stresses, Int. J. Fatigue, 27, 119. http://dx.doi.org/10.1016/j.ijfatigue.2004.06.009.

[6] Z. Yu and X. Xu. 2005. Failure analysis of a diesel engine crankshaft, Eng. Fail. Analysis, 12, 487-495. http://dx.doi.org/10.1016/j.engfailanal.2004.10.001.

[7] G. Castro, A. Fern'andez-Vicente and J. Cid. 2007. Influence of the nitriding time in the wear behaviour of an AISI H13 steel during a crankshaft forging process, Wear, 263, 1375-1385. http://dx.doi.org/10.1016/j.wear. 2007.02.007.

[8] S. Ho, Y-L. Lee, H-T. Kang and C.J. Wang. 2009. Optimization of a crankshaft rolling process for durability, Int. J. Fatigue, 31, 799-808. http://dx.doi.org/10.1016/j.ijfatigue.2008.11.011.

[9] U. Jung, R. Schaal, C. Berger, H-W Reinig and H. Traiser. 1998. Predicting the fatigue strength of filletrolled crankshafts, Mat.-Wiss. U. Werkstofftech., 29, 569572. http://dx.doi.org/10.1002/mawe.19980291006.

[10] K.S. Choi and J. Pan. 2009. Simulations of stress distributions in crankshaft sections under fillet rolling and bending fatigue tests, Int. J. Fatigue, 31, 544-557. http://dx.doi.org/10.1016/j.ijfatigue.2008.03.035.

[11] S.Y. Sirina, K. Sirinb and E. Kalucc. 2008. Effect of the ion nitriding surface hardening process on fatigue behaviour of AISI 4340 steel, Mat. Charact., 59, 351358. http://dx.doi.org/10.1016/j.matchar.2007.01.019.

[12] R. Koneèná, G. Nicoletto and V. Majerová. 2008. Influence of nitriding on the fatigue behavior and fracture micromechanisms of nodular cast iron, Struct. Mater., 40(1), 75-78. http://dx.doi.org/10.1007/s11223-0080020-1.
[13] Y. Furuya, H. Hirukawa, S. Matsuoka, S. Torizuka and H. Kuwahara. 2008. Fatigue properties of nitrided ultrafine ferrite-cementite steels under rotating bending fatigue testing, Metall. and Mat. Trans. A, 39, 20682076. http://dx.doi.org/10.1007/s11661-008-9544-z.

[14] Metals Handbook - Metallography and Microstructures of Case-Hardening Steel, Vol. 9, ASM International.

[15] S. Baragetti, G.M. La Vecchia and A. Terranova. 2005. Variables affecting the fatigue resistance of PVD-coated components, Int. J. Fatigue, 27(10-12), 1541-1550. http://dx.doi.org/10.1016/j.ijfatigue.2005.06.011.

[16] S. Baragetti. 2007. Fatigue resistance of steel and titanium PVD coated spur gears, Int. J. Fatigue, 29, 1893-1903. http://dx.doi.org/10.1016/j.ijfatigue.2006. 11.005.

[17] J. Vetter, G. Barbezat, J. Crummenauer and J. Avissar. 2005. Surface treatment selections for automotive applications, Surf Coat. Tech., 200, 1962-1968. http://dx.doi.org/10.1016/j.surfcoat.2005.08.011.

[18] Y.L. Su, S.H. Yao, C.S. Wei, W.H. Kao and C.T. Wu. 1999. Comparison of wear, tensile, and fatigue properties of PVD coated materials, Mater. Sci. Tech., 15, 73-77. http://dx.doi.org/10.1179/026708399773002845.

[19] R.L. Norton. 2013. Machine Design, Prentice Hall, New Jersey.

[20] M. Guagliano, A. Terranova and L. Vergani. 1993. Theoretical and experimental study of the stress concentration factor in diesel engine crankshafts, $J$. Mech. Des., 115, 47-52. http://dx.doi.org/10.1115/1. 2919323.

[21] S. Baragetti, S. Cavalleri and A. Terranova. 2010. A numerical and experimental investigation on the fatigue behaviour of a steel nitrided crankshaft for high power IC engines, ASME J. Engg. Materials and Tech. 32.

[22] V. Leskovšeka, B. Podgornik and D. Nolan. 2008. Modelling of residual stress profiles in plasma nitrided tool steel, Mat. Charact., 59, 454-461. http://dx.doi.org/ 10.1016/j.matchar.2007.03.009.

[23] C.H. Gur. 2002. Investigation of the influence of specimen geometry on quench behaviour of steels by Xray determination of surface residual stresses, Int. J. Mech. Sci., 44, 1335-1347. http://dx.doi.org/10.1016/ S0020-7403(02)00051-6.

[24] J.A. Martins, L.P. Cardoso, J.A. Fraymann and S.T. Button. 2006. Analyses of residual stresses on stamped valves by X-ray diffraction and finite elements method, J. Mat. Proc. Tech., 179, 30-35. http://dx.doi.org/10.1016 /j.jmatprotec.2006.03.072.

[25] T.M. Charlton. 1973. Energy Principles in Theory of Structures, Oxford University Press.

[26] Abaqus 6.13 User's Guide, Dassault Systems, 2014.

[27] S. Baragetti. 2015. Design criteria for high power engines crankshafts, The Open Mech. Engg. J., 9, 271-281. http://dx.doi.org/10.2174/1874155X01509010271. 